\title{
Team Teaching in a Bilingual School: An Exploration of Teachers' Interpersonal Aspects and Student Classroom Interaction
}

\author{
Mr. Phongchayon Phoomwarin* \\ M.Ed. in Teaching English as a Global Language, Burapha University \\ 169 Bangsaen Rd. (National Highway 3137), Muang Chonburi, Thailand \\ Asst.Prof.Dr. Punwalai Kewara \\ Department of International Graduate Studies, Faculty of Education, Burapha University \\ 169 Bangsaen Rd. (National Highway 3137), Muang Chonburi, Thailand
}

\begin{abstract}
The purposes of this study were to explore the teachers' interpersonal aspects of team teaching in a bilingual program and to examine whether "team teaching" increases classroom interaction. The data was collected during course preparation and classroom instruction through classroom observations and individual semi-structured interviews. The participants were provided from the school and taught in English by selecting the same loading cognitive subjects to avoid the problems of difficult learning content. The participants were two pairs; pair one consisted of one native English-speaking teacher (NEST) and one non-native English-speaking teacher (NNEST), pair two consisted of two non-natives English-speaking teachers (NNEST). The findings indicated that the "Team Teaching" model was not the only advantage for the students and teamwork but the teacher's interpersonal aspects showed that when they had no choice to choose their team, and they might feel uncomfortable. The different cultures (Logistical), attitudes (Interpersonal), and teaching styles (Pedagogical) also made them felt uneasy to work in teams. Comparing two teams of the study, team consisting of two non-native English-speaking teachers built a better relationship than the other team. It was combined with gender factors, culture, teaching style, language barrier, communication, and attitude. It is obvious that pairing teachers is not an easy job. School administrator should consider various factors in order to help the team work effectively and successfully. They expressed feelings of working as a team through various factors. Therefore, the results of this study indicate that a good team should follow the model type as "Team Teaching".
\end{abstract}

Keywords: Team teaching, Pedagogical, Bilingual Education, Interpersonal, Classroom interaction

DOI: $10.7176 / \mathrm{JEP} / 11-33-15$

Publication date: November $30^{\text {th }} 2020$

\section{Introduction}

The Thai government realizes the importance of education in Thailand in response to the change in globalization. The Thai government has identified the need for curriculum reform to develop bilingual personnel and realize the outside world. English becomes a global and English integrated program is unavoidable, regular Thai-based programs do not meet learners' needs. Also, the ascent of the Association of Southeast Asian Nations (ASEAN) and the ASEAN Economic Community (AEC) is leading towards a single market and production base which increases the importance of English in Thailand. As stated in Article 34 of the ASEAN Charter, "The working language of ASEAN shall be English" (ASEAN, 2007). A bilingual or English Program is one major learning program in Thai education as Moore's research (2017) claimed that the Education Ministry of Thailand established two models of bilingual education, namely the English Program (EP) and the Mini English Program (MEP) in both public and private schools. EP and MEP are often referred to as bilingual programs, bilingual education, or bilingual schools. The increase in schools offering EP and MEP generates a greater need for EP and MEP teachers, as well as a suitable EP/MEP teacher education programs, which is the focus of this study. The Education Ministry of Thailand supports schools in recruiting EP and MEP teachers through acting as a recruitment center where both foreign and Thai teachers can apply for a teaching post (Ministry of Education, 2003).

In order to prevent incomprehension among learners, "Team Teaching Method" is considered in a certain context. The team-teaching is a teaching method where at least two teachers work together closely to prepare and teach students together in the same room or group. Students can spend more time with the teachers and get more individual attention. More than one teacher in class, makes it easier to teach students in smaller groups or one-onone (Morin, 2017). The purpose of using the team-teaching method in the class is to prevent problems because of language barriers in the classroom. The students need someone who is a translator to help them understand the content when the lesson is conducted by a foreign teacher. The researcher noticed that in a bilingual school, the Ministry of Education stated that all classrooms taught by foreign teachers must use English for most basic subjects except the Thai language and Thai history. Based on the above data, the researcher was interested in using more than one teacher in a classroom. Is it really necessary to use team teaching to develop students or does the learner only need another teacher as a translation assistant? 
According to Ngamsom (2007), there were four English Bilingual Education (EBE) models in Thailand; (1) English Plus (Native Speaker program): In this program, only the English language subjects are taught by native speakers of English. (2) Immersion Program: With this program some subjects are taught entirely in English. (3) English Integrated Studies (EIS): This model uses English as a medium of instruction to teach Computing, Mathematics and Sciences. (4) Bilingual Program: In this program some subjects are taught in English and some in Thai. This program combined Thai and foreign teachers to work in team. According to the Bureau of Education Innovation, Ministry of Education (2003), there are two types of bilingual program; The Mini English Program and the English Program.

EP and MEP are operated in mainstream schools (at pre-primary, primary, and secondary levels) and vocational schools. EP and MEP operated in public schools, private schools, Bangkok Metropolitan schools, and demonstration schools of the Faculty of Education of various universities (BIC, 2006). The differences between both programs were about MEP provides at least two core subjects in English (from eight subjects taught in school). The classes occupy at least 8-14 hours per week. EP provides at least four core subjects in English including English Language, Science, Mathematics, and Physical Education. Thai language and social studies with aspects related to Thai culture are taught in the Thai language. The classes occupy at least 15 hours per week.

The bilingual school which was the participant of this research, based teaching and learning on the basic core curriculum all subjects were taught in English called as an "English program (EP)" the teachers need to teach at least four core subjects in English. The classes occupy at least 20 hours per week.

As a school curriculum, an English program was organized with at least two teachers per class from kindergarten to sixth grade. One of them was a foreign teacher, which includes native English speaking and nonnative English-speaking teachers, and the other teacher was a Thai teacher. Fourth to sixth grade can be taught by only a foreign teacher because students are able to communicate, listen, and learn English well. The students do not need a language translator.

The participants' school employs the "Team Teaching" method in every classroom. There were two or more teachers teaching and planning together in the classroom. In working together as a team, the school administrator selected the working team for the teachers. There would be a meeting three days before the start of the semester to jointly plan lessons, divide the role of teaching in the team, and announce the names of the teachers in each team. It was inevitable because every subject and classroom had to be taught by two teachers in the classroom. The schools' policy allowed a foreign teacher would be the lead instructor in the classroom and another teacher was an assistant or translator. Both of them would have to work hard in communicating with each other. They have to learn about the culture of working together and learn different perspectives of work; including differences in teaching styles, attitudes, and language. This led many teachers felt uncomfortable and may one of the reasons they resigned. It was aligned with Moore's study (2009) which pointed out that differences in culture, nationality, language, and teaching style causes problems between individuals and makes them bored and increases teacher resignation rates due to the team-teaching strategy.

School administrators needed to recruit a large number of foreign teachers to teach English in every classroom. They needed an assistant teacher or translator to assure young learners who rarely expose to English in classroom. School administrators believe that students will not be overlooked and when students need help, another teacher will be able to assist immediately without disturbing the class. Their policy aligned with Moote (2003) who conducted research on classrooms in Japan with two or more teachers and the result found that some partners were able to work well together even if they did not choose their partner themselves.

Finally, this led to examining on the one hand the teachers' interpersonal aspects of team teaching in a bilingual program. Their perceptions about the program and themselves enabled an evaluation of the program from interpersonal aspects. One the other hand, to explore whether "team teaching" increases student classroom interaction in a bilingual program. Therefore, the findings may contribute to the development of effective teachers among the team to work together in a bilingual school.

\subsection{Research questions}

(1) What are the teachers' interpersonal aspects of team teaching in a bilingual program?

(2) Does team teaching increase student classroom interaction? How?

\section{Literature review}

\subsection{Types of Team Teaching}

According to the teaching theory (Morin, 2017) there are five basic team-teaching models as following;

1) Team teaching: Both teachers plan lessons and work together to teach students. This helps students see the teachers as equals. It also gives students the chance to ask questions and get assistance during a lesson. This can be especially helpful for students with accommodations.

2) One teaches, one assists and/or observes: Having one teacher actively teaching frees up the other teacher to assist and give individual help as needed. Or the other teacher can observe. For instance, an observing teacher may 
collect information about how a child responds to different teaching approaches and about his attention and behavior. That kind of data is valuable for IEPs and for behavior intervention plans.

3) Station teaching: Teachers may be responsible for different parts of the lesson plan. This allows them to play to their teaching strengths. Students are divided into groups and move from one station to the other. Or the teachers rotate from group to group.

4) Parallel teaching: The class is split in half, and each teacher takes one group. Both groups are taught the same thing but in a different way.

5) Alternative teaching: One teacher handles a larger group of students. Meanwhile, the other teacher works with a small group on a different lesson or gives more support to struggling learners.

The school selected as participant uses this type of "Team Teaching". Every classroom was composed of two teachers including native and non-native English-speaking teachers. They also make lesson plans, agreements and teach together in class.

\subsection{Successful Team Teaching}

According to Moore's study (2017), there are three factors that are related to the aspects of successful team teaching in order to explore the teachers' interpersonal aspects of team teaching.

2.2.1 Pedagogical

In a successful account of team teaching Carless (2006) reported that the two teachers; "met once a week to plan the next week's lesson, taking turns to bring suitable material and try to integrate the materials with the students' regular English lessons."

According to Carless's report, Moore (2017) highlighted two key factors apparent in successful team teaching; firstly, that working together and organization are key to the successful partnership; and secondly, the importance of keeping classes relevant to the students' real world by incorporating the lessons with the students' regular classes, thereby keeping a sense of purpose and relevance. This approach to team teaching was in the opinion of the NEST: "less stressful," "creates a warm atmosphere," and "really conducive to the learning process" This approach to the teaching partnership provides really useful examples of successful interactions in the target language, and gives them a range of different inputs and styles (Moore, 2017).

2.2.2 Logistical

The effort needs to be made to retain successful teachers, and in particular successful team-teaching partnerships, as it has been shown that these do improve over time (Carless, 2006). In this section, Moore (2017) noted that, the Thai government must support English language teaching. Especially the development of Thai teachers to participate in training or educational activities with foreign teachers as a native speaker. It is a certainty that investment from local schools informing positive relationships between teachers will help to promote longer lasting team partnerships, which can serve as role models to newer ones. It all about the role of teaching, teaching relationship, and using language for communication.

2.2.3 Interpersonal

Carless (2006) defined interpersonal factors that, "the ability to cooperate with partners, allied to sensitivity towards their viewpoints and practices, particularly when differences emerge". Moore (2017) presumed that "interpersonal" is the most significant as it could have the greatest impact on the other two. In fact, Carless's study of good practices in team teaching found the most successful classes were where the teachers (non-native and native speaker) were sensitive and displayed goodwill towards one another, were willing to let "points of tension subside," and were willing to compromise. However, because of different cultural backgrounds, this is not always easy to accomplish. Cultural clashes between native and non-native speakers involved in team teaching are quite common (Kwon, 2000). It all about cultural, emotional, attitude, thinking, conflict or mediation, team-working, negotiation, persuasion, influencing, problem solving and decision-making.

\subsection{Classroom Interaction}

Teaching is an interactive act, whereas interaction is the communication among teacher and students which runs continuously as responsive acts. Moore (2017) stated that in the classroom interaction and classroom activities, a productive class hour can be described as follows:

1. Learner-Content Interaction: Students work with materials or aids and attempt the task once again individually, in groups and so on.

2. Learner-Instructor Interaction: The teacher interacts with the whole class, group, pair or an individual student. 3. Learner-Learner Interaction: Students interact with each other: in groups, in pairs, as individuals or class.

\subsection{Learning Pyramid}

In addition to the types and definitions of classroom interaction, Dale (1985, as cited in Subramony, Molenda, Betrus, and Thalheimer, 2014) stated that Learning Pyramid theory could be used to analyze the stages of student interaction in the classroom. It helped us to see how the classroom interaction between teacher-student, student- 
student, and student-content and to analyze what level of theory which students were able to express their thoughts and participation in the classroom. So, the learning pyramid is a group of popular learning models and representations relating different degrees of retention induced from various type of learning. The representations are generally via percentages and discrete layers within a "pyramid of learning" (Subramony et al., 2014). Table1. Learning Pyramid

\begin{tabular}{|l|l|}
\hline Retention rate & Learning activity before test of knowledge \\
\hline $90 \%$ & Teach other: Teach someone else/use immediately. \\
\hline $75 \%$ & Practice doing: Practice what one learned. \\
\hline $50 \%$ & Discussion: Engaged in a group discussion. \\
\hline $30 \%$ & Demonstration: Watch a demonstration. \\
\hline $20 \%$ & Audio-visual: Watch audiovisual. \\
\hline $10 \%$ & Reading: Read the provided material \\
\hline $5 \%$ & Lecture: Listening to a lecture. \\
\hline
\end{tabular}

\section{Research Methodology}

3.1 Research design

This qualitative case study research uses a naturalistic approach that seeks to understand phenomena in the field (such as socially constructed knowledge) may describe such an instance of complex relationships between people, objects, and institutions. This is known as a case study (Stake, 1995).

The purpose of this case study, a form of qualitative research, was to understand human interaction between actors within a social unit, a single instance bounded by the case worker in the process of designing the research (Stake, 1995) and was applied to explore the current situation among teachers in team teaching and observe how team-teaching works in the classroom. The data collected through classroom observation while recording the video to see what were students interacting in class while teaching, and semi-structured interviews as Eisner (1991) stated that, good qualitative study can help us "understand a situation that would otherwise be enigmatic or confusing",

\subsection{Participants}

\subsubsection{Students}

Students in each classroom were in the sixth grade with the number of thirty-five per classroom. Almost all of them were eleven to twelve years old. Class A was eighteen boys and seventeen girls. Thirty-two students were Thai nationality and three girls were Filipino. Class B were fifteen boys and twenty girls. One girl was Filipino and the others were Thai nationality. They were studying in the English program and studying all subjects in the English language except Thai language and Thai history.

3.2.2 Teachers

The participants of the study were selected from the bilingual school using team teaching in the classroom. The teams were provided from the school administration and taught in the sixth grade in the English subject by selecting the same loading cognitive subjects to avoid the problems of difficulty learning content (Fundamentals of English and Reading and Writing).

Table2. Pairs of Teachers

\begin{tabular}{|l|l|}
\hline The $\mathbf{1}^{\text {st }}$ Pair \\
\hline 1 native and 1 non-native English-speaking teachers & The 2 ${ }^{\text {nd }}$ Pair \\
\hline Subject: Fundamental of English & \\
\hline
\end{tabular}

The participants were two pairs of two teachers worked in the academic year 2019-2020. The first pair was teaching the fundamentals of English, consisted of one native English-speaking teacher (NEST) and one nonnative English-speaking teacher (NNEST). The researcher referred to them as "Teacher A and Teacher B". The second pair was teaching in reading and writing, consisted of two non-natives English-speaking teachers (NNEST). The researcher referred to them as "Teacher C and Teacher D" 


\subsection{Data Collection}

\subsubsection{Lesson Planning Observation}

According to the theory of successful team teaching, Carless (2006) stated that, it is important that teachers' roles should be defined before entering the classroom and it is the responsibility of both partners to devise roles in relation to the qualities that they can bring to the class.

Team teaching was implemented since the lesson planning observation. This section was to investigate the teachers interpersonal aspects in the teams and to see the effectiveness of each team and comparison of the teachers' role when they taught in class. These aspects were observed during the lesson preparation among two teams as below, - How are they planning the lesson? (Objective, Contents, and Materials)

- What is the role of teaching?

- How are they communicating as a team?

- What language do they use to talk?

- What is the duty of each teacher in the team?

The lesson planning was observed two times before the class began. Teachers worked on content specification, skills, competencies, and materials to reduce tension in the classroom. Both teachers have appointed the role of teaching clearly. The lesson plan was submitted to the head of the foreign languages approximately one week in advance to check the content of the lesson before teaching. After that, teaching in the classroom was controlled and followed according to the plan. The lesson preparation was observed twice per pair. The second observation was to study the differences in the division of teaching roles of each team from the lesson planning preparation session and to observe the interpersonal aspects of the team such as do they agree with the agreement or how they deal with the situation. So, the researcher planned to observe this section two times to get enough information. Then the lesson plan was taken into the classroom by the researcher to record the incident whether it aligned with the plan or not.

3.3.2 Classroom Observation with Video Recorder

Two teams' classes were observed within the academic year 2019-2020. Each observation was one hour, started by looking through their plans and activities in the lesson plan. The researcher also put the camera at the back of the classes to observe student interaction while recording on the field notes all the descriptive information of the events, activities, pairs, and what happened at the site; reflective notes about my thoughts and the insights that came up during the observation. The researcher also observed what the teachers were doing in the classroom, how two teachers collaborated following the team-teaching theory, and how students reacted in the class. The video recording and field notes helped remind the researcher and were used for analysis to get the results.

The researcher also observed the behavior and expressions of teachers in the team to see their interpersonal aspects by following the team-teaching theory such as,

- What are the teachers doing in the classroom?

- How are two teachers collaborating with each other following the team-teaching theory?

- How are students interacting in the class?

- What kinds of students' learning is based on the learning pyramid theory?

The classroom interaction was observed between teachers-students, students-students, and the objectives of the lesson planning. Observations were conducted with all classes twice or until there was enough information. Then the results were analyzed after classes ended.

3.3.3 Semi-Structured Interview

The researcher conducted individual interview sessions with four participants in the English language which lasted 15-20 minutes. It was a face to face interview which allowed the teachers to talk in detail about their personal goals, feelings, and perspectives toward team teaching.

These semi-structured interviews were recorded with an audio recorder and used to ask each question only one time per person. The interview questions were set up in order to support the information from the observation part or to obtain some information that did not happen in class. Interviews helped to get the in-depth attitude of the participants, which cannot be obtained from observation.

\subsection{Data Analysis}

First, the researcher received the collected data from the lesson preparation observation, classroom observation and participants' interviews based on the keywords in literature review. The qualitative collected data was transcribed and coded then read the transcripts while listening to the recorded data to examine the data that the informants discussed most frequently. The researcher kept the identity of the informants anonymous. After that, the researcher coded the data by identifying the topics, issues or any similarities and differences throughout the data by making notes or highlighting on a hard copy of the transcript. The data were categorized and put into themes by emerging commonalities. Finally, the researcher analyzed the data by grouping identical data to answer the research questions. A summary of the information was written based on the theories presented in literature review. 
Lastly, cross-case analysis was to analyze the in-depth exploration of similarities and differences across cases with a view to support empirical generalizability and theoretical predictions. the researcher started with a definition or keywords of analysis and the objectives, then reviewed the most common proxy terms in the data and answered the research questions. The researcher conducted the first stage of cross-case analysis within case analysis by using a conceptual framework then reviewed the coding procedures, using empirical examples to illustrate the data with descriptive, interpretive and pattern codes when formulating generalizations within cases. In the second part, for the cross-case analysis the researcher searched for similarities and associations across case outcomes then transcribed and summarized. When empirically possible, cases were ordered by type, causal relationships between variables were explained and theoretical predictions. The researcher concluded with a critical appraisal of the methodology based on cross-case analysis and discuss best practices in reporting findings.

\section{Findings}

The findings are described into five aspects as follows;

\subsection{Pedagogical}

Pair 1 (one native and one non-native English-speaking teacher)

From Pair one's lesson planning observation, the team consisted of one native and one non-native teacher. They used English language for communication. This was the first time that they had worked together in a team. The non-native teacher was appointed as the leader in the class by agreement of both teachers. The native teacher was appointed as the assistant and also taught only a part of vocabulary and pronunciation. Both of them separated their role and duty unequally. They worked in a team as a type two of the team-teaching theory; One teaches, one assists and/or observes.

Pedagogical aspects also appeared in the classroom observation session. The two teachers worked together to arrange the tables and chairs to support their activity as planned. Team teaching helped them to be less stressful, created a warm atmosphere, and was really conducive to the learning process.

This can be noted that having more than one teacher in a room made the classroom management easier. Like rowing, if rowing alone, you will reach the shore slowly and easily tired. But if someone helps rowing the boat, it reaches the shore quicker it was a good thing to have someone to help along the way. The participants' interview stated that, team teaching means teachers within a team must be willing to share control of lesson plans, delivery of instruction, classroom management, and the classroom itself. Shared control can also mean shared credit as well as responsibility. Teacher B (NNEST) stated that,

"...you can back each other up. I know one of my teammates will be there. The classroom has three so I never worry if I have to take a day off because I know we are covered. So, it makes me feel relaxed, feel good."

Consequently, sharing work with a team teacher through the process of collaboration curbs feelings of burnout. Teacher A (NEST) maintained that, "I love it (team teaching) because it seems to take a lot of the burden off your shoulders and it will you take even way would to teach and I felt you can teach better because one team member will discipline students, one more to do like for me I can humor a few kids laughing. One more to do the talking at the moment. So, we divide the work carefully. So, I do the vocabulary then the Thai teacher will translate."

Pair 2 (two non-native English-speaking teachers)

This team consisted of two non-native English-speaking teachers. One was a Thai teacher and one was a Filipino teacher. They had never worked together in team. The Filipino teacher was a new teacher in the school. They used English language to communicate in team and were agreeing about the role of teaching together. The Thai teacher offered to be the leader in class and the Filipino teacher was a facilitator. The role of teaching also separated unequally as pair 1 . There were thirty-five students in class and they arranged the seats and tables different to pair 1 (another team). All students faced the blackboard. They did a type of the team-teaching theory; one teaches, one assists and/or observes.

During the observation session, Teacher C (NNEST) found it to be a relief that she and her team teacher are "both responsible for all curriculums." Further, while team teaching, Teacher D (NNEST) noticed, "To have two teachers, it is more hands on and one-to-one. In my classroom, it is now 35 versus 2, so the work is divided up." Teacher C's interview aligns with Teacher A's that, "I know that someone will cover the class when I absent or on leave. I sometimes fail to remember explaining the lesson, my partner would supplement the shortcomings. It is not so trying when others will support you. When I taught alone, I am a master of the class. I have to discipline the students, I have to explain everything, and I have to do the heavy things all by myself. Compared to the team, it is better for me to teach in the classroom."

From their answers, sharing instruction with a team teacher means that there are two sets of hands sharing the same amount of work, allowing for more meaningful instruction. As Teacher D stated that, "Although I did small groups before, having two credentialed teachers, we are able to hit more students and meet their needs. They receive more instruction." It means creating deep, interaction, and intentional learning experiences for students as a result of collaborating with a team teacher increases how effective teachers feel. Having two teachers in a 
classroom makes it easier to do the classroom management. Although they were working together for the first time in a team, they did their best to help each other. This is the advantage of teamwork that reduces stressful.

\subsection{Logistical}

Pair 1 (one native and one non-native English-speaking teacher)

It was about the collaboration of two teachers in the team based on the role of teaching, teaching relationship, and using language for communication. It also appeared during their interview, when two teachers in a classroom have different strengths, and take advantage of those differences as they plan and deliver instruction, they are modeling collaboration and teamwork for their students. While team teaching, participant Teacher A's (NEST) interview discovered, "I learned how to control the class. A good control on my partner."

Playing to each other's academic strengths also allowed team teachers to reach more students at once. Teacher B (NNEST) found that, "I refer to my old school, I think it is different when I teach alone. They are very attentive when they have a lot of teachers in class."

Not only does having a stronger academic background in certain areas benefit students, they believe that teamwork has strengths for teachers in supporting teaching. They are often unable to perform their teaching duties. It will be reduced to those who are worried because they are certain that at least someone will take care of the students. Teacher A (NEST) stated that, "Also, it allows you to be covered so there's something's going on like two poles and so I was allowed to go. I wasn't worried because I know my two teachers are there. If we have meetings typically at the end of the day sometimes, we have to go to a meeting and that's OK if you got backup you don't have to worry you know your covered so it's nice having two or three."

Working in a team requires synergy between both parties which will result in the best outcome. They feel motivated and at the same time accountable for the actions that will affect members of their team. Teacher A (NEST) stated that, "Co-teaching will help you know the role."

The division of teaching roles is an important issue to be aware. If anyone works too much, they may feel inequality. Therefore, teaching as a team, it should be clear about the role. They have to know their duties and perform their duties in order to avoid any delusion. The division of teaching duties is not just about teaching in yourself. As Teacher D puts it, "In the current team that I am assigned to, we change roles as the demand requires. Most of the time, I'm tasked to lead the class discussion."

Sometimes the teachers in the team must help each other in order to work efficiently and also help to reduce the conflicts in the team. Teacher A (NEST) showed that most teaching duties were Teacher B's (NNEST) which made her use a loud voice. So, he knew immediately that he had to help with teaching. It makes the team more active and benefits the team, like Teacher B (NNEST) said that, "I love my voice so when we teach in team, we can take turns. First Teacher A, I ask him about vocabulary, the next me I explain everything and after that I let my Thai partner translate in Thai. When I was not there it was so easy for me to let them cover the class. If you teach alone how about your student?"

The problem with this team was the unequal division of teaching roles after planning. This could probably assume that they had never worked together before and their relationship often got into difficulties. They learned the benefits of working as a team, but they also encountered difficulty in their working relationship.

Pair 2 (two non-native English-speaking teachers)

As Moore (2017) stated that team teaching is collaboration in action. The participants of this study all relied heavily on collaborating with their team teacher in order to build and prepare successful lessons, deliver instruction, manage student behavior, and meet students' needs. Team teaching as a mode of collaboration, allowed participants to model successful collaboration for their students. A participant in this study, Teacher C (NNEST)'s interview said, "We must plan the lesson before teaching in the class. We are working toward the same goal of teaching them. When I am missing something, my partner steps in. We are modeling collaboration"

The shared teaching role is the priority in teaching as a team. When they planned and divided their roles, they encountering an immediate situation. They must have a good relationship with each other in order to be flexible. During the class, the two teachers were not talking together. They just focused on their role. Most of the role teaching in the class was the duty of Teacher C (NNEST) as planned. Teacher D (NNEST) just helped explain to the student individually and walked to look after the students who did not follow. Sometimes Teacher D (NNEST) wanted to explain more about the content while Teacher C (NNEST) taught. They looked at each other as was a signal that she would like to talk a little more, Teacher C (NNEST) would nod and stop talking to signal that she already allowed.

\subsection{Interpersonal}

Pair 1 (one native and one non-native English-speaking teacher)

The interpersonal aspects appeared when two people work together with cultural differences, conflicts, attitudes, emotions, perceptions, team-working, negotiation, persuasion, influencing, problem solving and decision-making. Most of the cultural differences were about the foreign teachers not speaking and understanding Thai. The students 
sometimes need a teacher who speak Thai for better understanding of the complex contents. As Teacher B's (NNEST) interview said that, "I asked the teacher to translate this for the students because I think it is hard for them especially grammar.....Your teaching cannot flow because you must have someone to translate, someone to talk."

Not only communication between teachers and students but it can happen between partners who cannot use English to communicate. That means the relationship is reduced because they cannot communicate with each other. Therefore, the team's planning may not succeed because of the misunderstanding and miscommunication which aligns with Teacher A (NEST)'s ideal, “A little bit with the Thai teacher. She does not speak English when we communicate and for Teacher B that is no trouble because Filipino teachers are generally a little more fluent. If I slow down when I speak with my Thai co-teacher then she knows enough to understand whatever point she needs to make or I make. It works out OK."

Communication is important as I noticed, whether communication between teachers with one another or between students. Working in the classroom cannot be driven if they do not communicate. Although there are some benefits of team teaching among communication, they do not give up to turn away from the problem and keep it alone. They spend time during classes talking and consulting on the problem. I transcribed that they were adjusting towards each other. When teaching as a team they have to change every school year, most teachers are unable to choose the team that they want. Sometimes it is like gambling without you being able to know your future. As participant, Teacher A (NEST), put it, "It's a mixed blessing. Let's put it that way. The mixed blessing is that when you get a new partner, you get new ideals, you get new teaching styles, you get to learn from different things they know. But it is not too hard for me. I can pretty much blend with whoever and where ever. I think some people thought it would be hard because some people don't like change. For me I like change, I like to mix it up but that is just my personal style (to learn from each other)."

Team assignments are the responsibility of the school administrators in the placement of each teacher. It can have a big impact on collaboration if you cannot adjust to each other in your team. It is amazing to see them work together, even though they may not want to work as a team. Teacher B (NNEST) said that, "I want to teach alone but I have no problem. I can adjust and I can easily adapt. We should have a good relationship and good team work."

It would be better if the partners on the team were not random, but should also study the relationships and limitations of each teacher. If you have no choice, you need to be paired with someone you do not like. That may cause the relationship of the team to be ruined from the beginning. As Teacher A states "Some partners have a bigger ego. So, label all the talk time. And some partners are more shy or afraid to talk. But my partner now she is very great. I am very lucky...Compared to my old partners, they do meditation and make me sleepy also to the students. We are a different style."

The choice of teaching methods in schools is also based on the number of students. The attitude of teachers toward the size of the classroom is affected by classroom management because when there are more students in the room, they need an assistant to discipline students. The kinds of appropriate teaching method depend on the number factor. Teacher B (NNEST) realized that "It depends on the other factors; number of students, level, and size of the class. If you can do everything yourself. Why not? You can teach alone."

The attitude of team teachers may not always align with each other regarding classroom management, how to split responsibilities, how to deliver curriculum, and on the many other intricacies that are involved with teaching. However, when you have an established relationship that includes mutual respect, trust, and honesty, those disagreements can be easier to navigate. As Teacher A (NEST)'s interview case, he demonstrated that, you need to be open to hearing what your team teacher has to say when you disagree. He views team teaching as "an opportunity to extend yourself and learn from someone else and share ideas. It builds relationships." When you have a positive established relationship with your team teacher, you are more likely to be open to their ideas. When you are more open to their ideas, the relationship is more likely to be maintained.

Having different working styles was a major problem between teams. It was a small spot that can be spread to everywhere. If they can choose, they want to choose to pair with someone who has more similar styles. It makes work better. They conveyed these stories through perspectives that,

Teacher A: “.... Like my old partner, we worked different philosophically. She is a little stronger. As far as discipline I'm a little bit more. So, we talked together for a year and a half. Eventually, I am just got up or not each other style. So, it is better to pair me up with someone who is not of the different styles. Maybe a little more relaxed atmosphere that's where I thrive and give for someone a little bit more discipline that's where she thrives. So that's OK because our styles don't make either one of us bad. We just have different personalities."

Teacher B: “...but for me I prefer to stay with a Thai teacher. Because when he (Teacher A) disciplines the students, he is very different from me because I am very firm in discipline with the students. I am very strict but friendly. I am strict inside the classroom but outside I am friendly. So, we are contrasts. I disciplined the student at the same time he played with the students. So (it) makes the students not listen to me anymore. But if it is me and Thai teacher, the class will go smoothly. But anyway, he is cool and he likes listening to me also." 
This can be noted that they want to pair with someone who shares the same style. Some teams are broken because they could not get along well. Some people have to quit their jobs because they found a partner who is difficult to work with. From the story of the participants above, I realized that having different styles is a small matter but imagine that if you have to work together throughout the academic year, have to wake up to see each other every day. It would be quite uncomfortable and that may be one of the reasons why many people don't want to work as a team.

Pair 2 (two non-native English-speaking teachers)

A major problem in the interpersonal aspects was communication. Whether it was verbal communication, body language or communication which all helped the team work easier. The communication problem also occurred during pair 2's classroom observation. I noticed that sometimes teachers D (NNEST) pronounced unclearly. Teacher $\mathrm{C}$ (NNEST) used the method of repeating once again for the students and did not humiliate the other person. It seems that in this classroom there was an atmosphere of teachers and students and teacher to the teacher as well. The observations were aligned with participants' interview. Most of teachers had problems about the language barrier in the Thai community. In this team, they stated that they did not have communication problems if our team members can use English well as Teacher D's interview, "In my team, language barriers do not appear as a challenge, for we were composed of Filipino teachers, and a Thai teacher who lived in Australia for a number of years."

The participants pointed out that sometimes good teams do not necessarily get people they want to work with but more on a positive attitude to adapt and learn how to work with others. In the second classroom observation, the first thing that felt strange was that both teachers were wearing a blue shirt. I asked them about the color of the clothes. Teacher D (NNEST) said that "I wear clothes according to their daily colors" (Thai beliefs). I was surprised that Filipino teachers were able to understand and learn to adapt to the Thai community. Aside from teaching and learning in the room, maybe they have been living here and learned the school culture.

Also, a view of the other side makes them see the importance of the team even more. In particular, the size of the classroom. They realize that when there are many students in the classroom, they think that it is necessary to have more than one teacher who helps control the class. Teacher C (NNEST) explained,

"...the number of students also is a factor to consider because when I taught in my old school, we only had twenty students per class. So, I could do it by myself without a Thai or foreign teacher. Compared to this school we have thirty-five students it is larger and my level of the student's is also low. They obviously are attentive and have more energy."

All participants suggested working in team was better if they have the choice,

Teacher C (NNEST): I prefer two or more teachers in my classes because the content of my class is about reading and writing. So, I need someone to help me create the activities and discipline students.

Teacher D (NNEST): In my opinion, I think it is good for two or more teachers to actively facilitate a class, paired with the right activity that utilizes the students' abilities that challenges them.

On the other hand, the number of teachers also depends on the activities in the room. As the connection that my participants remarked that "Typically four might be a little tough for teaching in the class if you're doing the teaching part usually what I've noticed as we rely on one or two teachers."

The attitude toward team teaching sometimes causes some problems from past experiences. Therefore, it gave them the opinion that there should be more than one teacher in the classroom. Situations in schools are often unpredictable. As Teacher C (NNEST) explained that, "I prefer using team teaching. For example, when I taught English in my old school during the sound lab class, I taught alone in front of the class and I never knew that my two students, boy and girl, were reclining together at the back of the room. Suddenly, another teacher who saw them on the CCTV, walked in the class and complained to me. So, I was shocked and I did not see them do that because the sound lab room has higher partitions. So, I just thought about it and I think it is good for me if we have many teachers in the classroom to discipline them."

What Teacher C (NNEST) shows through her explanation above was the importance of accepting her limitations and weaknesses in different curricular area. By accepting that teaching as a team can help her control the class more easily. It gives her the opportunity to learn effective new methods of teaching in the new workplace. Opportunity to learn new ways is key to growth and feelings of efficacy as an educator.

During the class, classroom activities went smoothly until teacher C (NNEST) had to join an unexpected school meeting. The class was conducted by teacher D (NNEST) without any interruption. This situation was related to the interview of Teacher C (NNEST) that, “...you can back each other up. I know one of teammates will be there. The classroom has three so I never worry if I have to take a day off because I know we are covered. So that makes me feel relaxed, feel good."

According to the classroom observation, I noticed that, a major element to teaching in general is Attitude. This is also true when it comes to team teaching. Teacher C (NNEST) puts it, "Attitude is very important. I think teaching in team is all about a positive attitude."

Having a good attitude is good for teaching in the team. The expulsion of negative views helped her release 
the mistakes and leave them in the classroom, rather than taking them home with her. When she reflects on lessons, it allows her to see what she could do differently in the future. This ability to reflect on what went well and what could have gone better in a lesson leads to more effective future lessons when the teacher decides how to rectify what could have gone better.

In order to be open to learning from your team teacher, having a positive attitude must be a part of a teacher's process. Teacher B expressed, "Also I think I am Filipino so this is not my country, I have to change and adapt."

Teacher $\mathrm{C}$ also pointed out the importance of reflecting on learning experiences with their students. "We point out when things go well, and talk about why with the class. We really point out the good times." When Teacher $\mathrm{C}$ and her team-teaching partner choose to point out the good times and talk about why something went well, they are modeling a positive attitude and stressing its importance to their students. This gives their students the tools to do the same and learn from each other like their teachers do, creating a positive learning environment.

\subsection{Classroom interaction}

Pair 1 (one native and one non-native English-speaking teacher)

In this session, the teachers created such enjoyment in the classroom; they made students smile and laugh which drove them to be more relaxed and more interactive during the difficult topic. This classroom activity greatly increases the interaction in the classroom. The classroom is designed to be able to interact with all of learnerinstructor, learner-learner, and learner-content interaction students. Students acquired more than one skill based on the learning pyramid. Students have a discussion, analyze and practice. This class allows students to learn as much as 80 percent, according to the theory.

It was aligned with the interview session, along with lessons becoming more interactive, students also receive more direct and intentional instruction when two teachers deliver instruction simultaneously. Teacher B (NNEST) found, "There are more chances for a teacher to interact with students. We can each go to different groups, by myself, it's hard for me to see what everyone is doing."

Team teaching also helps students to increase their interaction. Students will increase their attention to study than to play or take a nap while studying. The classroom with teachers around the room is like a fence on the farm. The students' attention was directed to one or more teachers. Teacher A (NEST) also pointed out, "(In class) you have more people and more teachers to interact with. I noted the students will act maybe a little different with each teacher but interact with all and it's a good thing that's what I see because they are speaking more..."

Pair 2 (two non-native English-speaking teachers)

The types of interaction for pair 2 were of learner-instructor interaction and learner-content interaction. Students would be able to learn by listening and responding correctly to verify accuracy. Students learned only 5 to 10 percent from listening to the lecture and reading from a book according to the learning pyramid theory.

It may be because the subject's content was focused on reading. The students in this classroom were less interactive with each other than the first team. Students only read and answered questions from the teachers. By observing, the students in the class often ignored their studies. They were easily distracted from their classroom because the assistant teacher had to discipline them several times. Even though this kind of instruction plan was clear about how partners work in teams, the results of team learning were not much different from teaching without a team because another teacher only served as an assistant.

\subsection{Cross Case Analysis}

According to the results of the study, to answer the research question1: What are the teachers' interpersonal aspects of team teaching in a bilingual program? There are two sides from observation and interview. This study affirms the findings in the literature that state social capital is required for true and successful collaboration (Moore, 2017). Participants in this study reported that their team-teaching partner needed to be someone they respected and were friends with. They found that in order to feel comfortable and safe sharing a classroom with someone else, their relationship needed to be previously established.

Although this study aligns with much of the existing literature, there were some differences from what has been said before. The findings extend the literature in that team teaching, at the bilingual school, led to a successful and more collaborative school community that is synergistic. What the researchers found was astounding is team teaching based on teacher's personality does not work. Although they do not want to do as a team with the various factors studied, it was also found that they feel uncomfortable if teaching with a different attitude, different teaching styles, and different cultures and nationalities. There are also gender factors and other related conditions. But they cannot avoid these occurrences. The results related to Sturman (1992) showed that, "students in the English class were suffering as a different of teaching in team teaching lessons." It is like predicting or gambling in choosing a working partner. Interpersonal aspects were expressed in both behavior and perspective have a significant connection. The participants reported that, they felt more comfortable if they are paired with people of the same gender and culture. That also affected the teaching style. Although the problem in their mind was big or small, if they feel uncomfortable either with their partner, it will inevitably affect their duties in the classroom. 
Additionally, the school environment affects teachers to learn to adapt to the school policy. They do not have the opportunity to choose a partner and methods of teaching. Although they had previous work experience in both individual teaching and team teaching. They also have to adapt to the new situation. Because of that, they cannot choose a partner by themselves, it is the beginning of a problem that will arise within their mind. Schools should emphasize this issue first. They should have the authority to choose a team partner or agreed before teaching.

Besides, to the research question2: Does team teaching increase student interaction? How? Classroom Interaction. Two different teaching styles in a classroom might not work for the team but there might be benefits for the students as well. Teaching style was how instruction is delivered to students. Gardner's Theory of Multiple Intelligences states that people learn best when instruction is delivered to them in a manner that compliments their intelligence. Therefore, when there were two different styles within a classroom, students with varying intelligence are more likely to comprehend instruction. As Moore (2017, as cited in Pederson, 2017) claimed, "Because they have different styles, they can learn from each other to adapt teaching in the class and are able to meet the needs of more students."

Participants also found that there was more student interaction as a result of the team-teaching strategy because they took more time to plan their lessons, and instruction was delivered to students using multiple teacher styles, thereby reaching more students at once. Being able to reach more students also further increased the participants' feelings of efficacy.

Not only were team teachers able to reach more students with their different styles, but they were able to deliver more intentional instruction to students who were struggling or requiring a challenge. Team teaching allows teachers to pull students more easily for small group or one-on-one instruction because there were two credentialed educators in the classroom. While one teacher oversaw the whole group, the other was able to pull students and differentiate for those who need it.

\section{Conclusion}

According to the team-teaching model, there is a clear classification of teams in each category. Actually, all teams must use a teaching approach as a "team teaching type" follows the school policy. The observations showed that, when they worked in team, most teachers have unequal teaching assignments according to the definitions of "Team Teaching" (type 1). Some teams are assigned roles and duties with the one teacher as an assistant or observer (type 2 -one teaches, one assists and/or observes). Some teams share instruction with one teacher leading the classroom and a teacher who helps to teach only students who have problems or struggling learners such as type 5 (Alternative teaching).

Therefore, in order to make a team successful and give an equal role in teaching. Teachers who teach as a team should use the teaching approach of "Team Teaching" (type 1). It means two teachers have to plan the lessons together, divide equal teaching roles, and provide thorough student support.

\section{Discussion and Implications}

This study found that team teaching based on teachers' personality is not effective. Teams of different nationalities and genders have negative attitudes towards team teaching probably because of their terrible teamwork backgrounds. Team 1 consisted of an American teacher and a Filipino teacher. Both of them had previously worked in teams with a conflicting partner. The American teacher had worked with Thai teachers who were quite different in their teaching style. They often argued in the classroom. When he has to work as a team again, he saw team teaching as gambling. They always hope to get along with people with the same attitude. If he has to work with people he doesn't like, it may be more harmful to students than beneficial. While the Filipino teacher in team 1 had previously taught in a team with a British partner which made her view that working with native speakers made her feel insecure. She felt uncomfortable working with people with different teaching styles. Her expression made the researcher noticed that, her dissatisfaction with the partner may have been about her attitude towards the teaching team. She wanted to teach alone in the classroom but she had no choice. So, she only needed another teacher to help her translate or take control of the class, rather than someone else to help her teach.

On the other hand, the second pair consisted of two non-native teachers that were from different cultures and nationalities but they were non-native teachers and more interestingly that they were the same gender. They worked together better than Team 1. It might be because they had never taught in a team before. They learned from each other well and worked together without conflict. Although they did not divide the same teaching role, when teaching in unexpected situations they could do it well. Problems arising in the classroom of the second team may have caused them to see the benefits of team teaching. So, they were able to adapt and work together.

The problems that occurred in the team teaching were that they did not learn from each other. Working in a team was like forcing the teachers to follow school policies. Based on the observations and interviews with the participants, it was found that they acted as if they understood each other, but they just wanted to work as a team because it could ease the burden on them. If they can choose, in a classroom with a small class and the content was not complicated. They chose to teach alone because it made them feel more comfortable. But if the classroom 
has about 30-50 students, they would need another teacher to help control the class. The results showed that the teachers did not need a partner to help teach, but they needed a partner to help ease the burden. This allows them to understand that they like teaching as a team, and that team teaching can help ease the burden, which may actually have to be crossed with what they understand.

One more reason, based on the teaching team's definition. All of these misconceptions that arise may not be solely from the collaboration of the school partners, but may also include the unclear defining of the team teaching. School administrators understand that team teaching is when two or more teachers plan together and divide teaching roles with a foreign teacher or one of the teachers in team will be leading the classroom. According to Morin's theory, the formulation of this teaching method is defined in Type 2 which is One teaches, one assists and/or observes: Having one teacher actively teaching frees up the other teacher to assist and give individual help as needed. This was not a theoretically correct definition of the "team teaching" type. When teaching strategies in schools were unclear. This mistake would affect teams that have interpersonal conflicts. This study pointed out that it was important to emphasize the type of team teaching. It has little similarities and differences, but they have big consequences if we do not define them clearly.

In view of the increased student classroom interaction, when comparing the teaching of the two teams it was found that Teachers in Team 1, consisted of native and non-native teachers, plan a variety of teaching materials. They organized activities that enable students to engage in all three types of classroom interaction. Students in the classroom learned more not only by listening to the teachers, but they achieved up to 50 percent of their learning based on learning pyramid theory. Students interacted between the students and content when they have to find answers from the provided words on the board. They interaction between students and teachers when they are required to answer teacher questions from prepared materials. Lastly, they also interacted with each other as they were divided into discussion groups to help each other find the correct answer. The classroom in pair 1 showed an increase in the classroom interaction following the definition;

"the interaction in the classroom was occurred through teacher talk, questioning, giving feedback and discussion. It also for the teachers who plan the lessons and their activities that enhances the development of the two very important language skills which are speaking and listening among the learners" (Moore, 2017).

If compare with the definition of interaction that was mentioned above, student expression cannot be confidently called an increase in student interaction. This was because the interaction by definition occurred as the learner participates in the discussion and from 50 percent or more of the learning pyramid theory. It was a common practice for a class to be asked and answered. This can be called class participation or just a part of checking students' understanding. Therefore, classrooms in team 2 had less results from classroom interaction than team 1.

It can be concluded that Team teaching based on teachers interpersonally has not worked for all subjects in the school. Bilingual schools in Thailand may need only a team-teaching strategy as a type of "one teaches, one assist and/or observes" in the classroom. According to the results of the study, all participants gave a heavy attitude that they just need a team partner only to help control the class and share the workload. If students can use English for communication, one teacher may not need to assist in the classroom. Also, classroom interaction can be increased by using only one teacher in the classroom. They just need to be careful and meticulous in planning the content before teaching. This study shows that the increase in the interaction was not driven by team teaching, but it was enhanced by appropriate teaching activity design.

\section{Recommendations for Future Research}

Schools that use a team-teaching strategy, especially bilingual schools, should study definitions and correctly identify the type of team teaching. School administrators should be more aware of the teacher being comfortable because that was one problem that makes teachers get tired of their work and ultimately decide to resign. If the school chooses to use a type of team teaching, all teachers should receive equal teaching roles. Finally, the results of the teachers' teaching efficiency directly affect the student's learning. Schools should consider the appropriateness of hiring school teachers. If a single teacher can teach in one classroom, it may improve teacher performance because when one teacher was teaching while the other was only an assistant. Is it really necessary for every classroom to have more than one teacher?

Future research could explore team teaching in a different kind of community such as a regular school not only in a bilingual school or another area of education, high school, or university. Further research may study a different type of team-teaching model. Compared to the benefit of each type or find another solution to deal with team teaching.

Future studies may investigate the relationships among participants' gender factors affecting team teaching. Alternatively, study longer-term team relationships to determine the stage and development of relationships or interpersonal relationships among team participants and how they manage when faced with problems or conflicts in the team. It would be also interesting to study the relationship between people according to the diversity of nationalities, such as the study of the relationship between a team of native teachers.

Further research could also focus on what teachers need to know to rectify unmet needs so that they can team 
teach. If there is no embedded time to plan in their schedules, no shared space, and a weak collaborative community at their school, how can they effectively move forward with team teaching?

\section{References}

Act (1999). The basic education core curriculum B.E. 2551 (A.D. 2008). Bangkok: Printing Press of the Express Transportation Organization of Thailand (E.T.O.)

ASEAN (2007). Charter of the Association of Southeast Asian. Unofficial Text. Centre for international Law, 20(11), 1-36.

BIC (Bureau of International Cooperation, Office of the Permanent Secretary, Ministry of Education and the Institute for Population and Social Research, Mahidol University). (2006). Annual research report 2006: Skill development for English proficiency of Thai students for the requirement of international standards and academic competition.

Carless, D. (2006). Good practices in team teaching in Japan, South Korea and Hong Kong. System. 34, $341-351$.

Cook, L., \& Friend, M. (1995). Co-Teaching: Guidelines for Creating Effective Practices. Focus on Exceptional Children. 26, 3.

Eisner, E. W. (1991). The enlightened eye: Qualitative inquiry and the enhancement of educational practice. New York. NY: Macmillan.

Friend, M. \& Cook, L. (2010). Interactions: Collaborative skills four school professionals. 6th Ed., Boston: Pearson Education.

Kwon, O. (2000). Korea's English education policy changes in the 1990s: Innovations to gear the nation in the 21st century. English Teaching. 55, 47-92.

Ministry of Education. (2003). Basic Education Curriculum 2003. Bangkok: Kurusapa Ladprao Publishing.

Ministry of Education. (2008). Basic Education Curriculum 2008. Bangkok: Kurusapa Ladprao Publishing.

Moore, B. (2009). Perceptions of identity and foreign language use in Thai hotel workers: Insight into sociocultural understandings of foreign language learning. Language Institute Journal. 4, 19-41.

Moore, B. (2017). Exploring the merits of team teaching in Thai classrooms: A critical reflection on practice in East Asia. LEARN Journal: Language Education and Acquisition Research Network. 10(1), 118-133.

Moote, S. (2003). Insights into team teaching. The English Teacher: An International Journal, 6(3), 328-334.

Morin.A. (2017). Collaborative Team Teaching: What You Need to Know. Retrieved from https://www.understood.org/en/learning-attention-issues/treatments-approaches/educationalstrategies/collaborative-team-teaching-what-you-need-to-know.

Ngamsom, S. (2007). The Effectiveness of Bilingual Education in Basic Education Curriculum, Sufficiency Economy Philosophy Applied: English for Integrated Studies (EIS) Model, A Case Study. Retrieved from http:/sites.google.com/site/surapongeisth/Home/the-effectiveness-ofbilingual-education-in-basiceducation-curriculum--sufficiency-economy-philosophy-applied.

Stake, R. (1995) The Art of Case Study Research, Thousand Oaks, CA: Sage Publications.

Sturman, P. (1992). Team teaching: Acase study from Japan. In Nunan, D. (Ed.) (1992). Collaborative language learning and teaching. Cambridge University Press.

Subramony, D., Molenda, M., Betrus, A., \& Thalheimer, W. (2014). The Mythical Retention Chart and the Corruption of Dale's Cone of Experience. Educational Technology. 54(6), 6-16. 